\title{
IMPACTOS SOCIOAMBIENTAIS DA FUMICULTURA NO MUNICÍPIO DE VENÂNCIO AIRES, RIO GRANDE DO SUL, BRASIL: REVISÃO BIBLIOGRÁFICA
}

\author{
SOCIO-ENVIRONMENTAL IMPACTS OF TOBACCO FARMING IN VENÂNCIO AIRES \\ MUNICIPALITY, RIO GRANDE DO SUL, BRAZIL: BIBLIOGRAPHIC REVIEW
}

\author{
IMPACTOS SOCIOAMBIENTALES DEL CULTIVO DE TABACO EN EL MUNICIPIO DE \\ VENÂNCIO AIRES, RIO GRANDE DO SUL, BRASIL: REVISIÓN BIBLIOGRÁFICA
}

Francine Kist Closs ${ }^{1}$

Cássio Michelon ${ }^{2}$

\begin{abstract}
Resumo
O município de Venâncio Aires e região é conhecido no Brasil como um grande produtor de tabaco. Devido à produção em larga escala do plantio de fumo, muitos estudos afirmam que a região é alvo de volumes excessivos de agrotóxicos e diversas intoxicações - o que deixa o município no topo dos índices de depressão e suicídio. Além dos agravos à saúde, sabe-se pouco sobre a situação ambiental da região e quais implicações a produção de tabaco causaria ao meio ambiente do entorno. O objetivo deste trabalho é buscar informações já existentes sobre os impactos socioambientais da fumicultura no município de Venâncio Aires, Rio Grande do Sul, Brasil. A metodologia utilizada no artigo foi de revisão bibliográfica, com busca de dados e comparações sobre o assunto. Alguns trabalhos apontam que a população sofre com os impactos negativos resultantes da fumicultura. Como resultado, notou-se que o município em questão dispõe de poucas pesquisas recentes e satisfatórias sobre o tema; entretanto, a problemática da fumicultura demanda atenção. Necessita-se, dessa maneira, de mais investigações que aprofundem os impactos socioambientais que ocorrem em Venâncio Aires, para um melhor esclarecimento e a correta tomada de decisões para atenuar esses problemas.
\end{abstract}

Palavras-chave: Fumo. Agrotóxicos. Impactos ambientais.

\begin{abstract}
The municipality of Venâncio Aires and region is known in Brazil as a major tobacco producer. Due to its largescale production of tobacco plantations, many studies claim that the region is the target of excessive volumes of pesticides and various intoxications - which puts the city at the top of the rates of depression and even suicide. In addition to health problems, very little is known about the environmental situation in the region and what implications tobacco production would have on the surrounding environment. The objective of this work is to search for existing information on the social and environmental impacts of tobacco farming in the municipality of Venâncio Aires, Rio Grande do Sul, Brazil. The method used was that of bibliographic review, with search for data and comparisons on the subject. Some studies indicate that the population suffers from the negative impacts resulting from tobacco farming. As a result, it was noted that the city in question has little recent and satisfactory research on the topic; however, the problem of tobacco farming demands attention. Thus, more investigations are needed to deepen the socio-environmental impacts that occur in Venâncio Aires, for better clarification and the correct decision making to mitigate these problems.
\end{abstract}

Keywords: Tobacco. Pesticides. Environmental impacts.

\section{Resumen}

El municipio Venâncio Aires y región es conocido en Brasil como gran productor de tabaco. Dada la producción del tabaco a larga escala, muchos estudios afirman que la región recibe volúmenes excesivos de agrotóxicos y sufre con diversas intoxicaciones - lo que genera para el municipio altos índices de depresión y suicidio.

\footnotetext{
${ }^{1}$ Pós-Graduação Gestão Ambiental e Desenvolvimento Sustentável (UNINTER). E-mail: francloss@ gmail.com.

${ }^{2}$ Mestre em Botânica (UFPR). E-mail: cassio.michelon@gmail.com.
} 
Además de su repercusión sobre la salud, se sabe poco sobre la situación ambiental de la región y sobre los efectos que la producción de tabaco produce en el medio ambiente. El objetivo de este trabajo es buscar informaciones acerca de los impactos socioambientales del cultivo de tabaco en el municipio Venâncio Aires, Rio Grande do Sul, Brasil. La metodología utilizada fue la revisión bibliográfica, con búsqueda de datos y comparaciones sobre el tema. Algunos trabajos informan que la población sufre con los efectos negativos del cultivo de tabaco. Como resultado del estudio realizado, se pudo constatar que el municipio dispone de escasas investigaciones, recientes y satisfactorias, sobre el tema; sin embargo, la problemática del cultivo de tabaco requiere de atención. Se hacen necesarios estudios que diluciden los impactos socioambientales que se producen en Venâncio Aires, para más conocimiento del problema y para que se tomen decisiones correctas en el sentido de atenuar esos problemas.

Palabras-clave: Tabaco. Agrotóxicos. Impactos ambientales.

\section{Introdução}

As lavouras de tabaco no Brasil são responsáveis pelo sustento de mais de um milhão de pessoas, o que totaliza 2,5 milhões de empregados em toda cadeia produtiva. Atualmente, o Brasil é o maior produtor de tabaco da América Latina e a região Sul concentra mais de 99\% das vendas para o exterior (MDIC, 2016). Estima-se que os cerca de 719 municípios produtores possuem em média 138.150 propriedades, distribuídas entre 185.160 famílias (AFUBRA, 2016). Por muitos anos, o município de Venâncio Aires, no Rio Grande do Sul, liderou o ranking dos maiores produtores de tabaco do país; entretanto, em 2016, perdeu este posto para o munícipio de Canguçu. Na safra de 2016/2017, Venâncio Aires somou 22.832 toneladas colhidas por 4.421 agricultores (AFUBRA, 2016).

Devido a estudos anteriores (CARGNIN et al., 2016; ETGES, 2002; FALK, 1996) e à crescente preocupação ambiental da população, sabemos que a agricultura também traz impactos negativos ao meio ambiente onde está inserido. Até então, sabemos pouco sobre os impactos que a fumicultura vem causando no município de Venâncio Aires, porém, estudos recentes têm demonstrado que graves problemas estão relacionados ao plantio de tabaco, tanto para o meio ambiente quanto para a saúde dos agricultores. Neste sentido, torna-se importante para os habitantes de Venâncio Aires e região conhecer os problemas advindos desta atividade, para buscar melhorias na qualidade de vida da população e do meio ambiente do entorno.

O tema abordado analisa e discute os impactos socioambientais derivados do plantio de tabaco no município de Venâncio Aires, Rio Grande do Sul, Brasil. Este estudo foi feito com dados baseados para o município de Venâncio Aires e sua relação com a fumicultura na região. Foram investigados os impactos ambientais e sociais decorrentes desta atividade no município.

\section{Fundamentação teórica}


A espécie Nicotiana tabacum L., é uma planta da família Solanaceae, nativa da América do Sul, na qual a folha seca da planta é usada para fumar, mascar ou aspirar (SOARES, et al., 2008).

A cultura do tabaco no Rio Grande do Sul teve início com a chegada dos imigrantes alemães no século passado. Em 1918, esta atividade já se consolidava em Santa Cruz do Sul, quando se instalaram usinas de beneficiamento do tabaco (HERMES, 2000). No ano de 2014, cerca de 719 municípios brasileiros apresentavam áreas com cultivo de tabaco, sendo que 90\% da produção nacional estava localizada na Região Sul (IBGE, 2014). Nos estados do Paraná, Santa Catarina e Rio Grande do Sul, cerca de 65\% dos municípios são produtores de fumo, sendo em torno de $96 \%$ da produção nacional (ABIFUMO, 2016). Na Tabela 1 podemos ver um panorama destes dados no Brasil.

\begin{tabular}{lccccr}
\hline \multirow{2}{*}{ Região } & \multicolumn{5}{c}{ Tabela 1 - Fumicultura brasileira, safra de 2016/2017. } \\
& $\mathbf{N}^{\mathbf{0}}$ de & FAMÍLIAS & HECTARES & PRODUÇÃO & Partic. \\
\cline { 2 - 6 } Estados & Produtoras & Plantados & Toneladas & $\%$ \\
\hline Nordeste & 3 & 150.240 & 298.530 & 705.930 & 98,1 \\
\hline Outras & 7 & 13.690 & 12.330 & 13.242 & 1,8 \\
\hline Total & 14 & 164.290 & 270 & 220 & 0 \\
\hline
\end{tabular}

Fonte: AFUBRA, IBGE (2019).

“A produção agrícola pode ser afetada por diversas pragas, como insetos, patógenos e plantas invasoras. Para combater estes organismos, são utilizados produtos químicos como inseticidas, fungicidas, acaricidas, nematicidas, bactericidas e vermífugos" (ALVES FILHO, 2002; SANTOS; PHYN, 2003 apud BOHNER; ARAÚJO; NISHIJIMA, 2013, p. 329).

A fumicultura já foi muitas vezes questionada quanto às reais possibilidades de promover melhorias na qualidade de vida, devido, principalmente, ao uso excessivo de agrotóxicos, ao grande esforço físico exigido no manejo da cultura e à elevada mão de obra em certas épocas do ano (AGOSTINETTO et al., 1998). O Brasil é o maior consumidor mundial de agrotóxicos, dado estimado pelo volume comercializado no país. Os trabalhadores expostos a esses produtos são numerosos, sendo as intoxicações agudas o maior impacto na saúde (FARIA; FASSA; FACCHINI, 2007).

Para Abdala \& Gossenheimer (2012), uma das principais causas de insatisfação e de busca por alternativas entre os fumicultores diz respeito aos riscos e possibilidade de intoxicação dos mesmos pelo uso de agrotóxicos. O Ministério da Saúde estima que, no Brasil, anualmente, existam mais de quatrocentas mil pessoas contaminadas por agrotóxicos, 
com cerca de quatro mil mortes por ano (MOREIRA et al, 2002). Segundo Almeida \& Soares (1992), quanto mais humilde e menos instruída for a família, maior a chance de haver casos de intoxicação, devido ao desconhecimento e despreparo dos agricultores.

Por mais que o fumo seja uma importante fonte de renda para muitas famílias brasileiras, a produção de tabaco requer um uso intensivo de agrotóxicos. Sabe-se que o uso de pesticidas em larga escala provoca danos à saúde dos agricultores, além de danos ao meio ambiente, como contaminação do solo, da água, desmatamento e perda de biodiversidade (SCHOENHALS et al., 2009).

Os agrotóxicos, também denominados xenobióticos, usados no controle de pragas, ao atingirem o solo estão sujeitos a processos de volatilização, lixiviação, escoamento superficial e degradação (fotoquímica, química e biodegradação), entre outros (SILVA et al., 2004). Segundo Miranda, (2007), estima-se que as populações que habitam áreas próximas aos locais de cultivo, e os moradores urbanos também estão significativamente expostos aos efeitos nocivos provocados pelos agrotóxicos.

No ano de 1999, no Brasil, foram registrados 4.135 casos de intoxicação humana por agrotóxicos na agricultura, resultando em torno de 140 óbitos; assim, dentre os casos registrados, 1.487 aconteceram na região Sul (SINITOX, 2003). Os fumicultores têm um maior risco de desenvolver alterações neurocomportamentais associadas ao uso de agrotóxicos, o que pode evoluir para quadros de depressão e suicídio (FARIA et al., 2014).

Conforme Fialho (2006), há diversos pontos negativos no trabalho da lavoura de fumo, como: o contato com a folha úmida do tabaco, a não utilização de equipamentos de proteção, o cheiro que exala as folhas do fumo, o contato com o veneno no período da aplicação, a necessidade de ficar acordado para cuidar dos fornos durante a secagem, as atividades pesadas de arar e lavrar, o calor e o sol quente na lavoura e os movimentos constantes de abaixar e levantar para retirar as folhas.

Entre os malefícios do tabaco, devido às condições de trabalho na lavoura, destacamse lesões musculoesqueléticas, distúrbios respiratórios, DFVT (Doença da Folha Verde do Tabaco) e doenças mentais (PERONDI et al., 2011). Cargnin et al., (2016), demonstrou em seu estudo que de 100 fumicultores amostrados, 18\% destes apresentaram sinais e sintomas de depressão leve e $2 \%$ de depressão moderada.

Moraes (2014), em seu estudo, destaca questões relativas à sustentabilidade ambiental do plantio de tabaco: 


\begin{abstract}
Muitos problemas são ocasionados em virtude da grande área destinada à cultura do tabaco, bem como, devido ao alto aporte de insumos externos utilizados na produção convencional. A manipulação dos ecossistemas naturalmente diversificados, em decorrência das perturbações inerentes ao processo de produção do tabaco, em geral resulta na simplificação da estrutura do ambiente (monocultura), na fragmentação do habitat e, principalmente, na redução da biodiversidade do local. Consequentemente, essa alteração acaba por gerar uma instabilidade ecológica, que por sua vez, acarreta problemas fitossanitários relacionados, principalmente, ao aumento das populações de insetos-praga e à diminuição de inimigos naturais, uma vez que as características intrínsecas de auto-regulação dos ecossistemas naturais, proporcionadas pela biodiversidade, são comprometidas ou perdidas (MORAES, 2014, p. 17).
\end{abstract}

Há muitos anos, o homem maneja os ecossistemas naturais para o exercício da agricultura, modificando-os em agroecossistemas. Em um agroecossistema, a biodiversidade é a base dos sistemas de produção, na qual se incluem as plantas cultivadas, plantas naturais do meio, animais, microrganismos e demais fatores como clima e geografia (AGUIARMENEZES, 2004). Nestes sistemas, a biodiversidade proporciona serviços ecológicos, como a ciclagem de nutrientes, o controle do microclima, a regulação de processos hídricos, a detoxificação de químicos nocivos e a regulação de organismos indesejáveis (ALTIERI, 1999).

Além da simplificação da estrutura do ambiente sobre áreas extensas, na qual resulta em um ecossistema que requer constante intervenção humana, a biodiversidade também é afetada por meio das externalidades ligadas ao uso intenso e desregrado de agroquímicos com o intuito de aumentar a produtividade (ALTIERI, 1999). Grande parte dos agricultores não ignora que a fumicultura traz problemas de saúde e de degradação ao meio ambiente, além da insatisfação constante que nutrem em relação aos preços que recebem das empresas. Parte deles se disporia a cultivar outras lavouras, se houvesse boas condições de crédito e apoio na comercialização (BREITBACH, 2014).

Para os pequenos e médios agricultores, o plantio de fumo tem se tornado uma alternativa viável devido a estes não terem recursos nem área suficientes para investir em outras culturas (SCHOENHALS et al., 2009). Para Etges, (2002), quanto maior a dependência econômica em relação ao tabaco, maior será o consumo de agrotóxicos, e consequentemente, mais comprometidas ficam as condições de saúde dos agricultores. Com a saúde comprometida, os agricultores terão poucas condições de investir em alternativas à cultura do tabaco ou na diversificação de suas atividades.

Venâncio Aires é um município brasileiro, situado no centro do estado do Rio Grande do Sul. Possui em torno de 65.964 habitantes e se estende por $773,2 \mathrm{~km}^{2}$. É considerado a "capital nacional do chimarrão", devido à produção de erva-mate, sendo também um dos maiores produtores de fumo do Brasil (CIDADE BRASIL, 2016). 
O tabaco atualmente é o principal gerador de renda em Venâncio Aires — o que garante recursos acima da média nacional para os pequenos produtores (OLÁ JORNAL, 2018). A produção média por hectare na safra de 2017/2018 é de 2,3 toneladas, com 9 mil hectares de área cultivada no município (EMATER, 2018).

Por muitos anos, Venâncio Aires esteve entre os maiores produtores de tabaco no Brasil, como mostra a Tabela 2:

Tabela 2 - Maiores municípios produtores de tabaco

\begin{tabular}{lll}
\hline Região Sul & Produtores & Produção (tons) \\
\hline Canguçu (RS) & 4.739 & 16.631 \\
\hline São Lourenço do Sul (RS) & 3.462 & 14.433 \\
\hline Venâncio Aires (RS) & 4.050 & 13.757 \\
\hline Canoinhas (SC) & 2.773 & 11.279 \\
\hline Santa Cruz do Sul (RS) & 3.611 & 10.888 \\
\hline Itaiópolis (SC) & 2.414 & 10.715 \\
\hline Candelária (RS) & 3.092 & 10.547 \\
\hline Camaquã (RS) & 2.323 & 10.469 \\
\hline Vale do Sol (RS) & 2.706 & 10.439 \\
\hline Rio Azul (PR) & 2.660 & 10.013 \\
\hline
\end{tabular}

Fonte: Olá Jornal (2018).

Historicamente, além da produção de fumo, Venâncio Aires tem altos índices de suicídio. Em 2017, um dado apurado pela Vigilância Epidemiológica do município mostrou que um suicídio ocorreu a cada 20 dias (FOLHA DO MATE, 2017).

No Brasil, o Rio Grande do Sul apresenta os maiores coeficientes de mortalidade por suicídio, e o grupo profissional mais atingido é o de agricultores (MENEGHEL et al., 2004). Os índices de suicídio são alarmantes, o que leva Venâncio Aires a ter um dos maiores números de casos por cem mil habitantes no Brasil e até no mundo (FALK, 1996).

Um estudo de Falk (1996), apresenta fortes indícios da relação entre a utilização de agrotóxicos organofosforados no cultivo do tabaco e o aumento das taxas de suicídio em Venâncio Aires. O estudo aponta que mais de $80 \%$ dos suicídios no município ocorreram entre agricultores. Em relação aos problemas ambientais, o uso intenso de agrotóxicos no cultivo do fumo em 1995, devido à uma seca, passou da média de 50 a $60 \mathrm{~kg}$ por hectare para $100 \mathrm{~kg}$ por hectare. Outro dado importante nos diz que justamente nos meses de outubro, novembro e dezembro foram os meses com maiores taxas de suicídio, que coincide com os meses em que mais se utilizam agrotóxicos nas lavouras. O grande índice de suicídio do 
município, mais o grande número de intoxicações, leva à graves consequências em relação à saúde dos fumicultores da região (FALK et al., 1996).

\section{Metodologia}

O método escolhido para o estudo foi o de pesquisa bibliográfica e revisão de literatura. Segundo Linde \& Willich (2003), um estudo de revisão é uma forma de pesquisa que utiliza dados da literatura sobre determinado tema.

Este tipo de pesquisa permite buscar diversos artigos, trabalhos, livros e páginas na internet referente ao assunto, na qual pode-se fazer uma análise comparativa que trará mais dados e conhecimentos sobre o tema. A pesquisa foi realizada entre os meses de abril e julho de 2018, na Biblioteca Virtual da Universidade de Santa Cruz do Sul - UNISC e demais sites de pesquisas acadêmicas. Optou-se preferência por trabalhos regionais de Venâncio Aires e Santa Cruz do Sul, principalmente trabalhos realizados por acadêmicos e professores da UNISC. A busca e seleção dos artigos foram realizadas utilizando as palavras-chaves: tabaco, Venâncio Aires, agrotóxicos e impactos ambientais fumicultura.

\section{Resultados e discussão}

Os lençóis freáticos subterrâneos podem ser contaminados por agroquímicos devido à lixiviação da água e da erosão dos solos. Esta contaminação também pode ocorrer superficialmente, devido à "conexão" dos sistemas hídricos, o que faz com que possam atingir áreas distantes do local de aplicação do agrotóxico (BRIGANTE, 2002; VEIGA et al., 2006). Portanto, a contaminação de um sistema hídrico não representa só a contaminação da água consumida pela população local, mas também a contaminação de toda a população que venha a ser abastecida por este sistema hídrico (VEIGA et al., 2006).

Etges, (2002) realizou uma pesquisa para levantar dados socioambientais e de saúde dos agricultores expostos à cultura do tabaco na Região do Vale do Rio Pardo. Dentre os principais resultados, destacam-se a alta concentração de manganês no solo da região, que poderia estar relacionado ao uso de pesticidas. Outro ponto importante, a ser destacado no estudo, diz respeito aos agricultores, na qual $86 \%$ da população amostrada já teve exposição crônica (direta) com agrotóxicos.

Moreira et al., (1996 apud RAMOS, 2013, p. 2) afirma que o manganês é um elemento essencial ao homem, atuando na formação dos ossos e tecidos, função reprodutiva e metabolismo de carboidratos e lipídios, porém a exposição crônica a este metal pode afetar o 
sistema nervoso central. Os principais efeitos são as desordens neurológicas associadas à exposição ambiental ou ocupacional ao manganês. Além do manganês, outro agente de intoxicação é a nicotina, que quando entra em contato com a derme do trabalhador rural pode causar um conjunto de sintomas conhecido como "green tobacco sickness" (GTS) ou doença da folha verde (ARCURY et al., 2003).

Estudos hidroquímicos em águas subterrâneas em municípios do Rio Grande do Sul, incluindo Venâncio Aires, apontam que aproximadamente $20 \%$ dos poços tubulares possuem altas concentrações de fluoreto (LOBO et al, 1998). Casos de fluorose dentária foram identificadas em mais de 300 crianças de comunidades rurais de Venâncio Aires, abastecidas por águas do Sistema Aquífero Guarani, segundo estudo de Silva (2001). Devido à alta carga de fertilizantes que a cultura do tabaco demanda, surgiu a hipótese se as altas taxas de fluoreto do Aquífero Guarani estariam ligadas ao cultivo de tabaco da região.

No entanto, Marimon (2006), em seu estudo, preconiza que as elevadas concentrações de fluoreto no aquífero em questão não são decorrentes de fertilizantes, e que sua origem deve estar relacionada com águas de circulação profunda que capta o flúor de minerais ricos deste elemento, como a fluorita.

Exposição à agentes genotóxicos no meio ambiente podem causar diversos efeitos sobre a saúde. Alguns efeitos se expressam imediatamente enquanto outros levam anos para se manifestarem, como câncer, doenças genéticas nas gerações seguintes e desordens de desenvolvimento (MALUF; ERDTMANN, 2003). Silva (2011) demonstrou em seu trabalho que a exposição a múltiplos pesticidas utilizados na fumicultura — incluindo a nicotina —, é responsável por efeitos genotóxicos e mutagênicos entre os indivíduos expostos.

Cargnin et al., (2016) realizou um estudo em um município no Sul do Brasil com 100 fumicultores; destes, $67 \%$ relataram sinais e sintomas relacionados à doença da folha verde do tabaco, 66,7\% alterações na coluna, 25\% doenças cardíacas, 25\% problemas respiratórios e 20\% sintomas de depressão. Houve uma associação estatística significativa entre os problemas de saúde e os anos vividos na lavoura de fumo. Outro trabalho realizado por Soares et al., (2003), com agricultores de Minas Gerais, constatou através de análise sanguínea que $50 \%$ dos trabalhadores entrevistados estavam intoxicados.

Poluição de mananciais, solos contaminados e diversos casos de intoxicações são apenas alguns dos problemas advindos do uso de agrotóxicos. Estas consequências, muitas vezes, são condicionadas pelo contexto e modo de produção quimiodependente, pelas relações de trabalho, pela toxicidade dos produtos utilizados e de micronutrientes contaminados, pela precariedade dos mecanismos de vigilância da saúde, pelo uso inadequado ou falta de 
equipamentos de proteção. Esta situação ainda é agravada pelas precárias condições socioeconômicas e culturais da maioria dos trabalhadores rurais, que ampliam sua vulnerabilidade à toxicidade dos agrotóxicos (SILVA et al., 2005; SOBREIRA \& ADISSI, 2003).

Em um estudo de Ferreira (2006), realizado no município de Santa Cruz do Sul, vizinha de Venâncio Aires, destaca-se a quase ausência de investimentos públicos que busquem melhorias para as condições de vida no campo, como por exemplo: a conscientização dos fumicultores em relação à sua condição de trabalho, a promoção de atividades culturais, esportivas e de lazer para a família, a instalação de mais escolas públicas de nível médio, ações que visem a melhoria das condições da saúde e programas específicos para os agricultores.

Embora tenha crescido nos últimos anos, a pesquisa brasileira sobre o impacto do uso de agrotóxicos na saúde humana ainda é insuficiente no tocante à extensão da carga química de exposição ocupacional e à dimensão dos danos à saúde decorrentes do uso intensivo desses agroquímicos. Um dos maiores problemas é a falta de informações sobre o consumo de agrotóxicos e a insuficiência dos dados sobre intoxicações por esses produtos (FARIA et al, 2007).

Porém, este quadro pode vir a melhorar se algumas práticas forem adotadas na fumicultura. Algumas técnicas podem ser listadas para melhorias da agricultura, tais como: controle biológico de pragas, uso de sistema float e de leito de substrato, manejo da agroecologia, biorremediação de solos e outros sistemas de produção sustentável (SILVA et al., 2004; HEEMANN, 2009; MORAES, 2014).

A diversificação de culturas pode ser uma boa estratégia de desenvolvimento socioambiental para os agricultores e para o futuro da região; porém, essa diversificação encontra várias dificuldades de implantação: muitos fumicultores se sentem seguros no sistema integrado do fumo, além da rentabilidade ser superior em relação às demais lavoura - o que torna a diversificação um impasse (BREITBACH, 2014). As dificuldades podem ainda ser mais expressivas entre as atividades alternativas embasadas na produção e na comercialização de produtos ecológicos, basicamente porque há uma maior execução de serviços na lavoura de fumo à base convencional, ou seja, por esta atividade demandar mais tempo, até finalizar o seu ciclo de produção (SILVEIRA, 2003).

Pela razão de plantar mais fumo, os agricultores podem desistir de projetos de transição ecológica, devido quase sempre, à falta de manutenção de renda em níveis 
satisfatórios dos produtos da produção ecológica, além da insegurança de mercado para esses produtos (LIMA, 2012).

Atualmente, um dos desafios da agricultura é promover o aumento da biodiversidade através da agricultura sustentável, por meio do restabelecimento e da conservação de habitats não agrícolas nas unidades de produção. Uma das técnicas mais utilizadas para essa finalidade é o controle biológico conservativo, na qual consiste na manipulação do ambiente para aumentar a sobrevivência, a fecundidade, a longevidade e a eficiência dos inimigos naturais de artrópodes-praga (LANDIS et al., 2000; PFIFFNER; WYSS, 2004).

Agricultura orgânica é um termo utilizado para designar a forma de manejo sustentável de agroecossistemas, objetivando a preservação ambiental, a conservação da biodiversidade, a manutenção dos ciclos biogeoquímicos e a qualidade de vida humana (MINISTÉRIO DA AGRICULTURA, 2015). A biodiversidade é a base dos sistemas de produção em agroecossistemas, na qual se incluem as plantas cultivadas, as plantas espontâneas, os animais, os microrganismos, entre outros componentes bióticos que podem variar de acordo com fatores antrópicos, socioeconômicos, climáticos, edáficos e geográficos, encontrados no meio agrícola e no seu entorno (AGUIAR-MENEZES, 2004).

Nesse sentido, o manejo do agroecossistema deve ser realizado de modo a aperfeiçoar o potencial local. Portanto, as estratégias do controle biológico conservativo buscam a sustentabilidade e a menor interferência possível no meio ambiente. Para usar de forma efetiva a biodiversidade no Manejo Integrado de Pragas (MIP) é importante saber que, tanto o tipo como a abundância da biodiversidade desejável na agricultura podem diferir de um agroecossistema para outro (ALTIERI, 1999; VENZON et al., 2005).

Populações microbianas como fungos e bactérias são conhecidas pelo seu grande potencial em biodegradar certos tipos de agrotóxicos. Para Silva et al., (2004) a biorremediação de solos contaminados pode ser uma boa estratégia para degradar os agroquímicos do meio, envolvendo reações oxidativas, redutivas e hidrolíticas. Essas reações garantem as vias de degradação, podendo variar de acordo com os degradadores, as condições ambientais e metabólitos formados.

Além de técnicas para remediar os agroquímicos utilizados no plantio, há também sistemas que demandam menor uso de agrotóxicos, que é o caso do sistema Floating de produção. Neste sistema, as mudas são plantadas em bandejas de isopor, as quais são enchidas com substrato, em uma lâmina d'água de 8 ou 16 centímetros, em um túnel coberto por plástico (UNIFUMO, 2018). Nessa lâmina da água são diluídos os venenos, fungicidas e 
fertilizantes, formando um concentrado químico, no intuito de reduzir a quantidade de agrotóxicos necessários na produção de mudas. (HEEMANN, 2009).

Vale lembrar que houve uma redução no uso de agrotóxicos, mesmo que tímida, e que as indústrias fumageiras realizam campanhas para o descarte correto de embalagens de agrotóxicos, assim como a erradicação do trabalho infantil nas lavouras (BONATO, 2007). Ainda assim, os resultados dessas ações, no que dizem respeito tanto à preservação dos ecossistemas como melhorias das condições de trabalho dos agricultores, são ainda incipientes (SCHNEIDER et al., 2013).

Para Lima (2012), o cenário das alternativas ao fumo ainda é incerto. Além do componente econômico já conhecido, os agricultores em geral convivem com os de natureza técnica, climática e interna às famílias, o que cria um obstáculo à evolução dos novos projetos, inclusive os que seguem os métodos e técnicas da agricultura convencional agroquímica. Ainda assim, os desafios para os agricultores não são intransponíveis, até mesmo para aqueles que se interessam pelo desenvolvimento da sustentabilidade na agricultura ou os que estão em transição agroecológica. Acredita-se que se deva desenvolver na região, uma experiência alternativa bem mais consolidada, ou mais atrativa no plano econômico, do que as que já estão postas no presente (LIMA, 2012).

O grande desafio da agricultura nos dias de hoje é saber usar de forma racional os recursos disponíveis no ecossistema, e identificar as melhores práticas de manejo dos sistemas agrícolas que venham a estimular a biodiversidade e favoreçam a geração de serviços ecológicos fundamentais, como: controle biológico de pragas, polinização, decomposição da matéria orgânica, reciclagem dos nutrientes, fixação biológica de nitrogênio, manutenção do microclima, regulação dos processos hídricos e conservação do solo. (MENEZES \& AQUINO, 2005).

Para Moraes (2014), é possível alcançar uma agricultura sustentável, produtiva e ambientalmente equilibrada, se apoiarmos práticas conservacionistas como estratégia para reincorporar a biodiversidade à paisagem agrícola, utilizando-se, principalmente, de sistemas consorciados, rotação de culturas, adubação verde, agricultura orgânica e plantas de cobertura ou, ainda, pela adoção de habitats não agrícolas, como faixas de plantas silvestres, cercasvivas, quebra-ventos, fragmentos florestais e vegetação natural preservada nas proximidades dos cultivos agrícolas.

Menezes \& Aquino (2005) também ressaltam que outro ponto chave para um sistema agrícola sustentável e energeticamente eficiente, é restaurar a diversidade da paisagem agrícola, tanto dentro como no entorno da propriedade rural, onde a diversidade deve ser 
melhorada com policulturas, sistemas agrossilvipastoris e matas ciliares. Com isso, haverá uma melhor regulação de pragas, reciclagem de nutrientes, conservação do solo, da água e menor dependência de agroquímicos (MENEZES \& AQUINO, 2005).

Felizmente, Santa Cruz do Sul já conta com inúmeras pesquisas e análises de excelente qualidade sobre a agroindústria do fumo, que nos fornecem elementos essenciais para a compreensão dessa realidade (BREITBACH, 2014). Cabe agora dar mais destaque ao município de Venâncio Aires, que merece igual atenção sobre este tema.

\section{Considerações finais}

Além de ser uma importante fonte de renda para famílias rurais, a produção de tabaco traz, também, impactos negativos, como comprometimento do desenvolvimento sustentável e riscos à saúde humana e ambiental, o que gera preocupação também com o ônus imposto aos segmentos economicamente menos favorecidos e ao sistema nacional de saúde (HERMES, 2000).

No decorrer do trabalho, pôde-se comparar diversos estudos, quase todos com um ponto em comum: os malefícios dos agrotóxicos na produção de tabaco na região e as graves consequências disso refletidas na população. Notou-se uma carência de trabalhos para o município de Venâncio Aires, o que dificultou descrever um adequado panorama local. Os dados a respeito do município e seu entorno sobre os impactos da produção de tabaco ainda são muito insuficientes, visto que a região onde Venâncio Aires está inserido é conhecida no Brasil todo como grande produtor de fumo.

Destaca-se o trabalho de Falk (1996), no qual se relata o alto índice de suicídio no município de Venâncio Aires, muitas vezes associado ao plantio do tabaco. Infelizmente, estes dados estão desatualizados e desde então, não houve nenhum outro trabalho significativo para Venâncio Aires que trate sobre o assunto. Neste sentido, é de extrema importância manter um banco de dados atualizado e confiável, principalmente no que diz respeito aos diversos casos de intoxicação por agrotóxicos, para então termos uma real dimensão do problema e buscar soluções mais específicas.

Além disso, pode-se observar em demais estudos, diversas práticas ambientais para a produção sustentável do tabaco, como a produção de fumo de forma ecológica, sem uso de agrotóxicos, que deveriam ser mais incentivadas entre os fumicultores, através da conscientização e preocupação com o meio ambiente e à saúde humana. Em uma cidade onde grande parte da economia é baseada na produção de tabaco, é necessário mais incentivo às 
pesquisas locais e bancos de dados relacionados aos impactos do setor fumageiro, pois uma vez que o meio ambiente da região não está ambientalmente equilibrado e sadio, a população vai continuar sofrendo as consequências e esperar por medidas satisfatórias.

\section{Referências}

ABDALA, Paulo Ricardo Zilio; GOSSENHEIMER, Agnes Nogueira. Reflexões sobre as lavouras de tabaco na perspectiva do desenvolvimento sustentável. Desenvolvimento em Questão, Rio Grande do Sul, v. 10, n. 19, p. 176-206, 2012.

ABIFUMO. Associação Brasileira da Indústria do Fumo. 2016. Disponível em: http://www.abifumo.org.br. Acesso em: 5 jul. 2018.

AFUBRA. Dados sobre a estrutura familiar dos plantadores de tabaco. 2016. Disponível em:

http://www.afubra.com.br/principal.php?acao=conteudo\&u_id=1\&i_id=1\&menus_site_id=16 . Acesso em: 21 jun. 2018.

AFUBRA; IBGE. Fumicultura Regional. 2019. Disponível em: https://afubra.com.br/sys/imprime.php?tabela=3. Acesso em: 21 jun. 2019.

AGOSTINETTO, D. et al. Utilização de equipamentos de proteção individual e intoxicações por agrotóxicos entre fumicultores do município de Pelotas - RS. Pesticidas: Ecotoxicologia e Meio Ambiente, Curitiba, v. 8, p. 45-56, 1998.

AGUIAR-MENEZES, Elen de Lima. Diversidade vegetal: uma estratégia para o manejo de pragas em sistemas sustentáveis de produção agrícola. Seropédica: Embrapa Agrobiologia, Brasília, n. 177, p. 68, 2004. Disponível em:

https://ainfo.cnptia.embrapa.br/digital/bitstream/CNPAB-2010/32098/1/doc177.pdf. Acesso em: 27 jun. 2019.

ALMEIDA, J. A.; SOARES, D. M. Análise das variáveis sociais na questão do uso dos agrotóxicos: o caso da fumicultura. Ciência \& Ambiente, São Paulo, v. 3, n. 4, p. 85-104, 1992.

ALTIERI, Miguel A. The ecological role of biodiversity in agroecosystems. Agriculture, Ecosystems and Environment, U.S.A, v. 74, n.1, p. 19-31, 1999. DOI:

https://doi.org/10.1016/S0167-8809(99)00028-6

ARCURY, Thomas A. et al. High levels of transdermal nicotine exposure produce green tobacco sickness in Latino farmworkers. Nicotine \& Tobacco Research. U.S.A, v. 5, p. 315321, 2003. DOI: https://doi.org/10.1080/1462220031000094132.

BOHNER, Tanny Oliveira Lima; ARAÚJO, Luiz Ernani Bonesso; NISHIJIMA, Toshio. O impacto ambiental do uso de agrotóxicos no meio ambiente e na saúde dos trabalhadores rurais. In: CONGRESSO INTERNACIONAL DE DIREITO AMBIENTAL E ECOLOGIA POLÍTICA, 1. SEMINÁRIO ECOLOGIA POLÍTICA E DIREITO NA AMÉRICA LATINA, 3., GPDS, 1981, Santa Maria. Anais [...] Rio Grande do Sul: UFSM, 2013. 
BONATO, A. A. A fumicultura no Brasil e a Convenção-Quadro para controle do tabaco. Curitiba: DESER, 2007. Disponível em:

http://www.deser.org.br/pub_read.asp?id=109. Acesso em: 5 jun. 2018.

BREITBACH, Áurea Corrêa de Miranda. A região de Santa Cruz do Sul e o fumo: panorama de uma "especialização" nociva. Indic. Econ. FEE, Porto Alegre, v. 42, n. 1, p. 43-62, 2014.

BRIGANTE, Janete; ESPÍNDOLA, Evaldo Luiz Gaeta; POVINELLI, Jurandyr; et al. Avaliação ambiental do Rio Moji-Guaçu: resultados de uma pesquisa com abordagem ecossistêmica. [S.l: s.n.], 2002.

CARGNIN, Marcia Casaril dos Santos et al. Cultura do Tabaco versus Saúde dos Fumicultores. Texto Contexto Enferm., Porto Alegre, v. 25, n. 2, p. 294-314, 2016.

CIDADE BRASIL. Munícipio Venâncio Aires. 2016. Disponível em: https://www.cidadebrasil.com.br/municipio-venancio-aires.html. Acesso em: 5 jun. 2018.

EMATER. Empresa de Assistência Técnica à Extensão Rural. 2018. Disponível em: http://www.emater.tche.br/site/servicos/informacoes-agropecuarias.php\#safra. Acesso em 14 jul. 2018.

EMATER. Empresa de Assistência Técnica e Extensão Rural. 2018. Disponível em: http://www.emater.tche.br/site. Acesso em: 7 jul. 2018.

ETGES, Virginia E. O impacto da cultura do tabaco no ecossistema e na saúde humana. Textual, v.1 n.1, p. 14-21, 2002. Disponível em:

https://www.sinprors.org.br/arquivos/7_17_2014_tabaco.pdf. Acesso em: 28 jun. 2019.

FALK, J. W. Estudo da Mortalidade no Município de Venâncio Aires, RS, no período de 1979 a 1991. 1996. 237 f. Dissertação (Mestrado em Medicina) - Universidade Federal do Rio Grande do Sul, UFRGS, Porto Alegre, 1996.

FARIA, Neice Müller Xavier; FASSA, Anaclaudia Gastal; FACCHINI, Luiz Augusto. Intoxicação por agrotóxicos no Brasil: os sistemas oficiais de informação e desafios para realização de estudos epidemiológicos. Ciênc. Saúde Coletiva, Rio de Janeiro, v. 12, n. 1, p. 25-38, 2007. DOI: https://doi.org/10.1590/S1413-81232007000100008.

FARIA, Neice Muller Xavier et al. Occupational exposure to pesticides, nicotine and minor psychiatric disorders among tobacco farmers in southern Brazil. Neurotoxicology, E.U.A, v. 45, p. 347-354, 2014. DOI: 10.1016/j.neuro.2014.05.002.

FERREIRA, M. A. F. Os produtores de fumo da Bacia do Rio Pardinho: o cotidiano subalterno e a difícil mudança. In: A produção de tabaco: impactos no ecossistema e na saúde humana na região de Santa Cruz do Sul, RS. Santa Cruz do Sul: EDUNISC, 2006. p. 170-194.

FIALHO, R. R. Os sentidos do trabalho para os agricultores e as agricultoras familiares de pequenas unidades produtoras de tabaco no município de Santa Cruz do Sul/RS. In: A 
produção de tabaco: impactos no ecossistema e na saúde humana na região de Santa Cruz do Sul/RS. Santa Cruz do Sul, RS: EDUNISC, 2006, p. 142-169.

FOLHA DO MATE. Venâncio Aires teve um suicídio a cada 20 dias neste ano. 2017. Disponível em: http://www.folhadomate.com/noticias/saude/venancio-aires-teve-um-suicidioa-cada-20-dias-neste-ano. Acesso em: 21 jun. 2018.

HEEMANN, Fabiane. O cultivo do fumo e condições de saúde e segurança dos trabalhadores rurais. $2009171 \mathrm{f}$. Mestrado (Dissertação do programa de Pós-graduação em engenharia de produção) - Universidade Federal do Rio Grande do Sul, Porto Alegre, 2009. Disponível em:

https://www.lume.ufrgs.br/bitstream/handle/10183/22063/000737926.pdf?sequence=1\&isAll owed=y. Acesso em: 28 jun. 2019.

HERMES, Nadir. Implicações socio-ambientais da fumicultura: panorama atual e perspectivas. Revista Redes, Santa Cruz do Sul, v. 5, n. 3, p. 45 64, 2000.

IBGE. Sistema IBGE de recuperação automática. 2014. Disponível em: http://www.sidra.ibge.gov.br/bda/agric/default.asp?z=t\&o=11\&i=p. Acesso em: 28 mai. 2018.

LANDIS, Douglas A.; WRATTEN, Stephen D.; GURR, Geoff M. Habitat management to conserve natural enemies of arthropod pests in agriculture. Annual Review of Entomology, v.45, n. 1, p.175-201, 2000. DOI: 10.1146/annurev.ento.45.1.175.

LIMA, Ronaldo Guedes de. Por que os projetos alternativos à fumicultura não vêm se tornando prioridade entre os agricultores do Vale do Rio Pardo, Rio Grande do Sul? Desenvolvimento em Questão, Rio Grande do Sul, v. 10, n. 19, p. 156-175, 2012.

LINDE, Klaus; WILLICH, Stefan N. How objective are systematic reviews? Differences between reviews on complementary medicine. Journal of the royal society of medicine, Berlin Germany, v. 96, n. 1, p. 17-22, 2003. DOI:

https://doi.org/10.1177/014107680309600105.

LOBO, E. A.; BACCAR, N. M.; COSTA, A. B.; KIRST, A. Estudo da qualidade da água de poços subterrâneos da região do vale do rio pardo e rio Taquari, RS, Brasil, com destaque para a concentração de fluoretos. Santa Cruz do Sul: UNISC, 1998.

MALUF, S. W.; ERDTRMANN, B. Biomonitoramento do dano genético em humanos. In: SILVA, J.; ERDTMANN, B.; HENRIQUES, J. A. P. (org.). Genética Toxicológica. Porto Alegre: Edito Alcance, 2003. 307-321 p.

MARIMON, Maria Paula Casagrande. O flúor nas águas subterrâneas da formação Santa Maria, na Região de Santa Cruz do Sul e Venâncio Aires, RS, Brasil. 2006. 314 f. Tese (Doutorado no Instituto de Geociências) - Universidade Federal do Rio Grande do Sul, UFRGS, Porto Alegre, 2006. Disponível em: https://lume.ufrgs.br/bitstream/handle/10183/7289/000541806.pdf?sequence=1\&isAllowed=y .Acesso em: 14 mai. 2019. 
MENEGHEL, Stela Nazareth et al. Características epidemiológicas do suicídio no Rio Grande do Sul. Rev. Saúde Pública, São Paulo, v. 38, n. 6, p. 804-810, 2004. DOI: https://doi.org/10.1590/S0034-89102004000600008.

MENEZES, E. L. A.; AQUINO, A. M. Coleoptera Terrestre e sua Importância nos Sistemas Agropecuários. Seropédica: Embrapa Agrobiologia, Brasília, n. 206, p. 55, 2005.

MINISTÉRIO DA AGRICULTURA. Agroecossistemas. 2015. Disponível em: http://www.agricultura.gov.br/desenvolvimento-sustentavel/organicos/o-que-e-agriculturaorganica. Acesso em: 12 jun. 2018.

MDIC. Ministério da Indústria. Comércio Exterior e Serviços. 2016. Disponível em: http://www.mdic.gov.br. Acesso em 24 jun. 2018.

MIRANDA, Ary Carvalho de et al. Neoliberalismo, uso de agrotóxicos e a crise da soberania alimentar no Brasil. Ciênc. saúde coletiva, Rio de Janeiro, v. 12, n. 1, p. 7-14, 2007. DOI: https://doi.org/10.1590/S1413-81232007000100002.

MORAES, Jonas. Comunidades de Coleoptera em Cultivos de Tabaco (Nicotiana tabacum L.) em Santa Cruz do Sul, RS. 2014. 136 f. Dissertação (Mestrado em Agrobiologia) - Universidade Federal de Santa Maria, UFSM, Santa Maria, 2014. Disponível em: https://repositorio.ufsm.br/handle/1/4885. Acesso em: 27 mai. 2019.

MOREIRA, Josino C. et al. Avaliação integrada do impacto do uso de agrotóxicos sobre a saúde humana em uma comunidade agrícola de Nova Friburgo, RJ. Ciência \& Saúde Coletiva, São Paulo, v. 7, n. 2, p. 299-311, 2002. DOI: https://doi.org/10.1590/S141381232002000200010.

OLÁ JORNAL. Área cultivada de tabaco em Venâncio Aires cresceu 2,59\%. 2018. Disponível em: http://olajornal.com.br/area-cultivada-de-tabaco-em-venancio-aires-cresceu259. Acesso em: 24 jun. 2018.

PERONDI, Miguel Angelo et al. Prospecção de meios de vida alternativos ao cultivo do tabaco no sudoeste do Paraná. Cadernos de Ciência \& Tecnologia, Brasília, v. 28, n. 3, p. 675-696, 2011. DOI: http://dx.doi.org/10.35977/0104-1096.cct2011.v28.16067.

PFIFFNER, L.; WYSS, E. Use of wildflower strips to enhance natural enemies of agricultural pests. In: GURR, Geoff M.; WRATTEN, S.D; ALTIERI, M. (org.). Ecological Engineering for Pest Management: advances in Habitat Manipulation for Arthropods. Australia: CSIRO Publishing, 2004. 256 p.

RAMOS, Thalita Dallapícula. "Avaliação da exposição ambiental ao manganês na população residente no entorno de um estaleiro no município de Angra dos Reis, RJ". 2013. 107 f. Dissertação (Mestrado em ciências na Saúde Pública) - Fundação Oswaldo Cruz, FIOCRUZ, 2013. Disponível em:

https://www.arca.fiocruz.br/bitstream/icict/24556/1/658.pdf. Acesso em 28 abr. 2019.

SCHNEIDER, S.; LIBARDONI, P. J.; PANDOLFO, G. As características e o perfil dos produtores de tabaco com base no Censo Agropecuário 2006. In: SILVEIRA, R. L. L. (org.). 
Tabaco, sociedade e território: relações e contradições no sul do Brasil. Santa Cruz do Sul: EDUNISC, 2013. 39-59 p.

SCHOENHALS, Marlise et al. Análise dos impactos da fumicultura sobre o meio ambiente, à saúde dos fumicultores e iniciativas de gestão ambiental na indústria do tabaco. Engenharia Ambiental, Espírito Santo do Pinhal, v. 6, n. 2, p. 16-37, 2009.

SILVA, Célia Maria Maganhotto de Souza; MELO, Itamar Soares de; FAY, Elisabeth Francisconi. Biotransformação de agrotóxicos e biorremediação. In: SILVA, Célia Maria Maganhotto de Souza; FAY, Elisabeth Francisconi. Agrotóxicos e ambiente. Brasília: Embrapa, 2004.

SILVA, Fernanda Rabaioli da. Risco ocupacional em fumicultores: genotoxidade associada à suscetibilidade genética. 2011. 171 f. Tese (Doutorado em Genética e Biologia Molecular) Universidade Federal do Rio Grande do Sul, UFRGS, Porto Alegre, 2011. Disponível em: https://www.lume.ufrgs.br/bitstream/handle/10183/49269/000835101.pdf?sequence=1\&isAll owed=y Acesso em: 15 jun. 2019.

SILVA, Jandira Maciel da et al. Agrotóxico e trabalho: uma combinação perigosa para a saúde do trabalhador rural. Ciênc. saúde coletiva, Rio de Janeiro, v. 10, n. 4, p. 891-903, 2005. DOI: https://doi.org/10.1590/S1413-81232005000400013.

SILVA, S. Poço afeta dentes de crianças: laudo comprova excesso de flúor no lençol freático. Zero Hora, Porto Alegre, 15 nov. 2001.

SILVEIRA, Rogério Leandro Lima da. Cidade, corporação e periferia urbana: acumulação de capital e segregação espacial na (re) produção do espaço urbano. Santa Cruz do Sul: Edunisc, 2003.

SINITOX. Sistema Nacional de Informações Tóxico-Farmacológicas: SINITOX. 2003. Disponível em: http://www.fiocruz.br/sinitox/2003/sinitox2003.htm. Acesso em: 11 jun. 2018.

SOARES, Edson Luís Carvalho et. al. Família Solanaceae no Parque Estadual de Itapuã, Viamão, Rio Grande do Sul, Brasil. Revista Brasileira de Biociências, Porto Alegre, v. 6, n. 3, p. 177-188, 2008.

SOARES, Wagner; ALMEIDA, Renan Moritz V. R.; MORO, Sueli. Trabalho rural e fatores de risco associados ao regime de uso de agrotóxicos em Minas Gerais, Brasil. Caderno de Saúde Pública, Rio de Janeiro, v. 19, n. 4, p. 1117-1127, 2003. DOI:

http://dx.doi.org/10.1590/S0102-311X2003000400033.

SOBREIRA, Antônio Elísio Garcia; ADISSI, Paulo José. Agrotóxicos: falsas premissas e debates. Ciênc. saúde coletiva, São Paulo, v. 8, n. 4, p. 985-990, 2003. DOI: https://doi.org/10.1590/S1413-81232003000400020.

UNIFUMO. Cultura do fumo. 2018. Disponível em: http://www.unifumo.com.br Acesso em: 16 jul. 2018. 
VEIGA, M. M.; SILVA, D. M.; VEIGA, L. B. E.; FARIA, M. V. C. Análise da contaminação dos sistemas hídricos por agrotóxicos numa pequena comunidade rural do Sudeste do Brasil. Caderno de Saúde Pública, v. 22, n.11, p. 2391-2399, 2006.

VEIGA, Marcelo Motta et al. Análise da contaminação dos sistemas hídricos por agrotóxicos numa pequena comunidade rural do Sudeste do Brasil. Cad. Saúde Pública, Rio de Janeiro, v. 22, n. 11, p. 2391-2399, nov. 2006. DOI: https://doi.org/10.1590/S0102$311 \mathrm{X} 2006001100013$.

VENZON, M. et al. Controle biológico conservativo. In: VENZON, M.; PAULA JÚNIOR, T. J.; PALLINI, A. Controle alternativo de pragas e doenças. Viçosa: EPAMIG, 2005. 1-22 p. 